\title{
Monoclonality of Parathyroid Tumors in Chronic Renal Failure and in Primary Parathyroid Hyperplasia
}

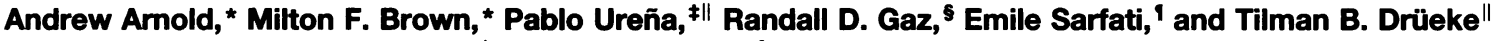 \\ ${ }^{*}$ Laboratory of Endocrine Oncology, ${ }^{\ddagger}$ Endocrine Unit, and ${ }^{\S}$ Department of Surgery, Massachusetts General Hospital and Harvard \\ Medical School, Boston, Massachusetts 02114; "Institut National de la Santé et de la Recherche Médicale, Unité 90, Prévention et \\ Traitement de l'Insuffisance Rénale, Département de Néphrologie, Hôpital Necker, Paris, France; and 'Service de Chirurgie Générale, \\ Hôpital Saint Louis, Paris, France
}

\begin{abstract}
The pathogeneses of parathyroid disease in patients with uremia and nonfamilial primary parathyroid hyperplasia are poorly understood. Because of multigland involvement, it has been assumed that these common diseases predominantly involve polyclonal (non-neoplastic) cellular proliferations, but an overall assessment of their clonality has not been done. We examined the clonality of these hyperplastic parathyroid tumors using $\mathrm{X}$-chromosome inactivation analysis with the M27 $\beta$ (DXS255) DNA polymorphism and by searching for monoclonal allelic losses at M27 $\beta$ and at loci on chromosome band 11q13. Fully 7 of 11 informative hemodialysis patients $(64 \%)$ with uremic refractory hyperparathyroidism harbored at least one monoclonal parathyroid tumor (with a minimum of 12 of their 19 available glands being monoclonal). Tumor monoclonality was demonstrable in 6 of 16 informative patients $(38 \%)$ with primary parathyroid hyperplasia. Histopathologic categories of nodular versus generalized hyperplasia were not useful predictors of clonal status. These observations indicate that monoclonal parathyroid neoplasms are common in patients with uremic refractory hyperparathyroidism and also develop in a substantial group of patients with sporadic primary parathyroid hyperplasia, thereby changing our concept of the pathogenesis of these diseases. Neoplastic transformation of preexisting polyclonal hyperplasia, apparently due in large part to genes not yet implicated in parathyroid tumorigenesis and possibly including a novel $X$-chromosome tumor suppressor gene, is likely to play a central role in these disorders. (J. Clin. Invest. 1995. 95:2047-2053.) Key words: uremia • primary hyperparathyroidism • secondary hyperparathyroidism • tertiary hyperparathyroidism • neoplasia-parathyroid
\end{abstract}

\section{Introduction}

Little is known about the pathogenesis of the common forms of multigland parathyroid disease in humans. These disorders

Address correspondence to Dr. Andrew Arnold, Endocrine Oncology, GRJ 1021, Massachusetts General Hospital, Boston, MA 02114. Phone: 617-724-3742; FAX: 617-724-2195.

Received for publication 13 April 1994 and in revised form 9 December 1994.

J. Clin. Invest.

(c) The American Society for Clinical Investigation, Inc.

0021-9738/95/05/2047/07 \$2.00

Volume 95, May 1995, 2047-2053 have traditionally been referred to as parathyroid hyperplasia, but the implicit assumption that such multigland involvement consists of true polyclonal responses to generalized growth stimuli may not be accurate in all instances. Furthermore, it is possible that in certain patients or glands an initially polyclonal hyperplasia may evolve into a monoclonal neoplasm, which might have more autonomous hormonal function or growth properties.

Common (nonfamilial) primary parathyroid hyperplasia is responsible for $\sim 15 \%$ of all cases of primary hyperparathyroidism; the term primary in this instance may simply reflect our ignorance of the stimuli driving a polyclonal expansion of all parathyroid cells. Alternatively, multigland involvement might bespeak a high likelihood of independent clonal neoplasms arising in each of a patient's glands. As was the case in the study of parathyroid adenomas (1) and multiple endocrine neoplasia type $1(\mathrm{MEN}-1)^{1}(2,3)$, an assessment of the clonality of parathyroid glands in parathyroid hyperplasia is likely to provide fruitful insights into its pathogenesis.

Uremic refractory secondary hyperparathyroidism is characterized by hyperfunctioning parathyroid tissue that no longer responds appropriately to physiological influences or usually efficacious medical therapy; the resulting autonomous PTH secretion may cause clinical problems like hypercalcemia, bone disease, or nephrocalcinosis (4). Parathyroid glands in this disorder might be true polyclonal expansions that have become so large that the summation of all cells' nonsuppressible basal secretion of PTH is excessive for the patient. Alternatively, clonal transformation may have, in essence, created an adenoma in one or more glands. One such clonal lesion was reported to occur in a small minority of uremic parathyroid glands (5) but a comprehensive examination of clonality in this disease has not been performed. In addition, parathyroid gland monoclonality or polyclonality might correspond to histologic patterns of nodular versus generalized hypercellularity; uremic patients with nodular parathyroid hyperplasia were reported to have a higher rate of recurrent hyperparathyroidism after surgical parathyroidectomy than uremic patients with purely diffuse hyperplasia (6).

Clonality can be assessed from the proportion of a woman's tumor cells in which a particular X-chromosome is inactivated. This method's utility does not depend on foreknowledge of the particular genes causing clonal transformation and has been widely validated in studies of many human tumors, including parathyroid adenomas and other endocrine tumors $(1,7-18)$. We used X-chromosome inactivation analysis to examine the clonal status of nonfamilial primary parathyroid hyperplasia and

1. Abbreviation used in this paper: MEN-1, multiple endocrine neoplasia type 1. 
uremic refractory hyperparathyroidism and also assessed these tumors for evidence of clonal DNA losses at specific loci.

\section{Methods}

\section{Patients and tumor specimens}

Primary parathyroid hyperplasia. We studied tumors from 16 unselected and unrelated women with a diagnosis of typical primary parathyroid hyperplasia. The mean age of the patients was $60.8 \mathrm{yr}$ (range $21-$ 80 ). All patients were hypercalcemic (average serum calcium $12.3 \mathrm{mg} /$ dl, range 10.7-14.7). All had elevated (or inappropriately normal) serum parathyroid hormone levels, which ranged from 0.7 to 15 times the upper limit of normal. No patient had a history of neck irradiation, features of a multiple endocrine neoplasia syndrome, or any family history of hyperparathyroidism. At surgery, multiple hypercellular parathyroid glands were identified and removed from each patient. Histopathological confirmation of multigland parathyroid hyperplasia was obtained in each case. No patient remained hypercalcemic postoperatively. Gland weights (data available for 10 tumors) ranged from 230 to $2,020 \mathrm{mg}$ ( mean $947 \mathrm{mg}$ ). Linear dimensions were available for the remaining 9 tumors, and weights were estimated from the regression $\mathrm{Wt}(\mathrm{g})=0.585 \mathrm{RV}\left(\mathrm{cm}^{3}\right)+0.134$, where $\mathrm{RV}$ is the product of 3 dimensions (19); inclusion of these estimated weights raised the combined mean weight to $1,396 \mathrm{mg}$. For 14 of the 16 patients, 1 gland (typically that patient's largest) was obtained for study. For one patient, two glands were available for study and for another patient three glands were available. For these cases, no gross or histopathologic distinction between nodular and generalized hyperplastic pattern was attempted by the surgeon or pathologist. In addition, we obtained a single gland from each of two male patients with primary hyperplasia. All patients with primary hyperplasia were operated on at the Massachusetts General Hospital.

Secondary parathyroid hyperplasia. We studied tumors from 11 female uremic patients with refractory secondary parathyroid hyperplasia. The mean age of these patients was $49.5 \mathrm{yr}$ (range 35-63). All patients were treated and operated on in Paris, France. All patients were on intermittent hemodialysis treatment for chronic renal failure. Parathyroid surgery was indicated because of severe secondary hyperparathyroidism associated with pruritus, radiologic evidence of osteitis fibrosa, soft tissue calcifications, hypercalcemia, hyperphosphatemia, and/or other symptoms and signs which were resistant to medical treatment (6). In no case was chronic renal failure a consequence of primary hyperparathyroidism. 7 of the 11 patients were hypercalcemic in the absence of calcium or vitamin D therapy, and 4 were normocalcemic. Serum PTH levels were markedly elevated in all instances (average 16fold above the upper limit of normal). Serum phosphate levels were elevated in 10 of the 11 patients. No patient had a family history of hyperparathyroidism or multiple endocrine neoplasia, or a history of head and neck irradiation. In all patients, multiple hypercellular parathyroid glands were identified and resected. These glands were categorized as either nodular hyperplasia or generalized hyperplasia by gross and histopathologic criteria (20-22). Gland sizes ranged from 30 to 5,980 mg. In 2 of the 11 patients, a 30 - and 700-mg parathyroid graft to the arm was available for study. One parathyroid gland was available for study from five of the patients; two glands each were available for study from two patients; and four glands each were available from two patients. In addition, we obtained 17 glands from 9 male patients with uremic refractory parathyroid hyperplasia. No male patient had a family history of hyperparathyroidism. Their mean age was $43.8 \mathrm{yr}$ (range 19-71).

Control, normal parathyroid glands. 15 normal parathyroid glands which required removal during surgery for thyroid disease or as biopsy specimens during surgery for isolated parathyroid adenoma were obtained from 14 women; one additional normal gland was obtained at autopsy from a victim of sudden cardiac arrest.

Peripheral blood leukocytes. Peripheral blood leukocytes were available from 10 of the patients with primary hyperplasia, 11 of the uremic patients, and from 8 randomly selected women without hematologic disease.

All tissue and blood specimens were obtained in accord with institutional human study procedures.

\section{DNA sample preparation}

All parathyroid specimens were frozen in liquid nitrogen shortly after surgical removal. High molecular weight DNA was extracted using standard procedures.

\section{M27 $\beta$ analysis of clonality}

$21 \mu \mathrm{g}$ of high molecular weight DNA from each sample was cut with restriction endonuclease PstI for $2 \mathrm{~h}$ at $37^{\circ} \mathrm{C}$. After treatment with phenol/chloroform and ethanol precipitation, the DNA was resuspended in $10 \mathrm{mM}$ Tris, $\mathrm{pH} 8,0.5 \mathrm{mM}$ EDTA and then split into three equal aliquots. One aliquot received no further treatment; one aliquot was further digested with restriction endonuclease $\mathrm{MspI}$ for $2 \mathrm{~h}$ at $37^{\circ} \mathrm{C}$; the third aliquot was further digested with $\mathrm{HpaII}$ for $2 \mathrm{~h}$ at $37^{\circ} \mathrm{C}$. To assure optimal activity of HpaII, a control sample, with an M27 $\beta$ band that HpaII can cleave completely, was included in each set of digests. In addition, selected samples with ambiguous M27 $\beta$ patterns that could have been caused by partial digestion with HpaII were redigested; we found that neither increasing the enzyme concentration, the final reaction volume, nor the duration of the digest reaction had any effect on the resultant Southern blot patterns. All DNA digests were loaded onto $0.8 \%$ agarose gels and electrophoresis was carried out for $\sim 20 \mathrm{~h}$ at 65 V. After electrophoresis, gels were stained with ethidium bromide and examined under ultraviolet light to assure complete digestion and even loading of samples. Southern blotting was performed with standard methodology, and blots were hybridized to ${ }^{32} \mathrm{P}$ random primer-labeled $\mathrm{M} 27 \beta$ probe $(23)$, washed at $55^{\circ} \mathrm{C}$ in $0.1 \times \mathrm{SSC}$ and $0.1 \%$ sodium dodecyl sulfate, and autoradiographed, as described previously (1). Autoradiographs were analyzed by densitometry, using a scanning laser densitometer (Pharmacia AB, Uppsala, Sweden). Allelic cleavage ratios were calculated based upon the change of intensity incurred by each of the two bands seen in the original PstI digest, quite analogous to the use of cleavage ratios in previous studies (1). A minimal allelic cleavage ratio of 3.5 was chosen to provide a stringent, conservative definition of a monoclonal pattern.

Clonality was also assessed by studying loss of heterozygosity at $11 \mathrm{q} 13$ and at M27 $\beta$. For $11 \mathrm{q} 13$ analysis, $\sim 3 \mu \mathrm{g}$ each of male and female patients' normal leukocyte DNA and tumor DNA was digested for $2 \mathrm{~h}$ at $37^{\circ} \mathrm{C}$ with MspI. Digested samples were loaded onto $1 \%$ agarose gels and electrophoresed for $16 \mathrm{~h}$ at $40 \mathrm{~V}$. After electrophoresis, Southern blotting was carried out as described above. Probes used for hybridization were PYGM (24) and D11S146 (25), obtained from the American Type Culture Collection (Rockville, MD). Loss of heterozygosity at M27 $\beta$ was assessed in PstI digests while carrying out Xinactivation analysis of patients' normal leukocyte and tumor DNA samples.

\section{Rationale for use of $M 27 \beta$ in clonal analysis}

As a first step, digestion of tumor DNA with PstI and subsequent probing with the M27 $\beta$ probe permits the two X-chromosome alleles of a woman to be distinguished. Subsequent digestion by the methylation-sensitive restriction enzyme HpaII, which cuts at its recognition sites only when such a site is unmethylated, allows clonal assessment. This is because the critical HpaII sites in the M27 $\beta$ region are methylated when present on the active $\mathrm{X}$-chromosome and are unmethylated, and thereby susceptible to digestion, when present on the inactive X-chromosome (2630 ). Of the three MspI sites in the M27 $\beta$ region (Fig. $1 A$ ), the M3 site is consistently methylated while M1 and M2 are partially or completely unmethylated on the inactive X-chromosome allele (9). Therefore, monoclonal tumors derived from a single progenitor cell will exhibit a highly preferential pattern of HpaII cleavage, since the X-inactivation pattern of the clonal progenitor is retained in all progeny that comprise 
A

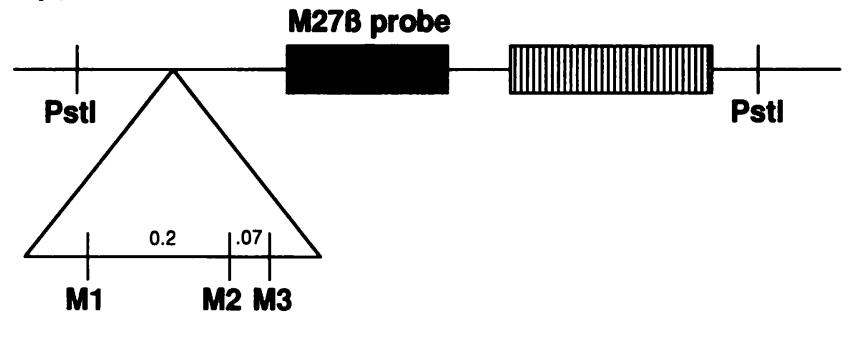

B

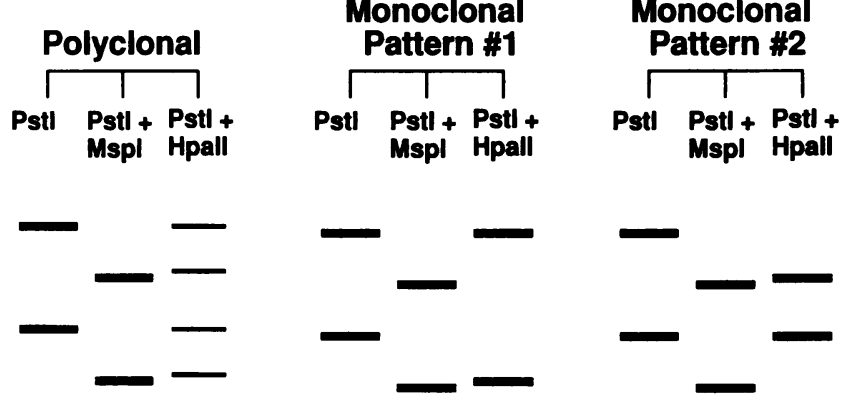

Figure 1. (A) Partial restriction map of the M27 $\beta$ locus (DXS255).

The variable number of tandem repeat region is indicated by stripes.

The 2.5-kb DNA fragment used as the hybridization probe is shown as a filled box. Cleavage sites for restriction enzyme PstI flank the locus. Of the three MspI/HpaII sites designated M1, M2, and M3, only M3 is consistently methylated at its internal cytosine and therefore resistant to cleavage with HpaII. The methylation of M1 and M2 varies in accord with location on the active versus inactive $\mathrm{X}$-chromosome (8). Intervals between MspI sites are given in kilobases. $(B)$ Schematic diagram of typical expected Southern blot hybridization patterns for $\mathrm{X}$-inactivation analysis using M27 $\beta$. A monoclonal tumor will only exhibit one of the two monoclonal patterns shown above. The PstI + MspI control is useful for marking the sizes of fully cleaved alleles.

the mature tumor (Fig. $1 B$ ). While polyclonal X-inactivation patterns need to be interpreted cautiously (see Discussion), positive findings of monoclonality using M27 $\beta$ are reliable and have shown excellent concordance with other, independent methods of clonal analysis $(9,31)$.

\section{Results}

Primary parathyroid hyperplasia: 15 of 16 women with primary parathyroid hyperplasia were informative with the M27 $\beta$ probe, yielding a total of 18 informative parathyroid glands. Five of these glands exhibited a convincing monoclonal $\mathrm{X}$-inactivation pattern, with an average allelic cleavage ratio of 13.8 (range 3.5-27.7) (Fig. $2 A$ ). The remaining 13 glands exhibited either a typical polyclonal or ambiguous pattern of $\mathrm{X}$-inactivation (average allelic cleavage ratio 2.1 ). Of the 15 informative patients, $5(33 \%)$ harbored at least 1 monoclonal gland as detected with this method. In addition, one patient's gland with an ambiguous M27 $\beta$ result later proved to be monoclonal based on loss of heterozygosity at 11q13, increasing the percentage of patients with monoclonal glands to $38 \%$. There was no correlation between detectable monoclonality and the size of parathyroid tumor, or serum calcium and PTH levels.

Secondary parathyroid hyperplasia. 11 of 11 patients with
A
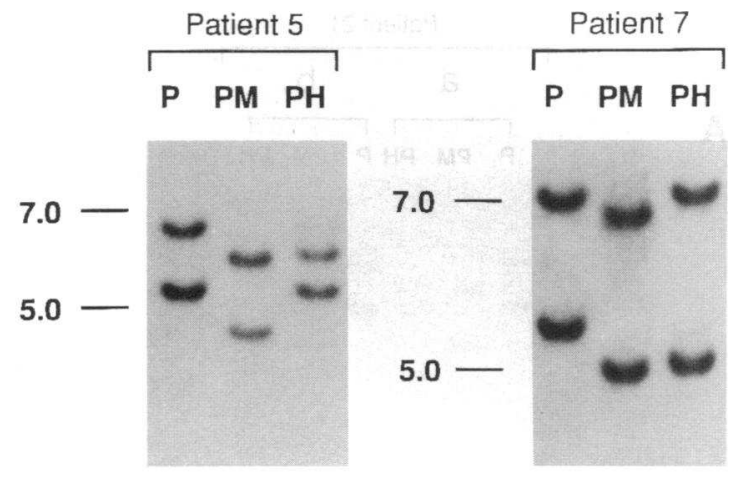

B

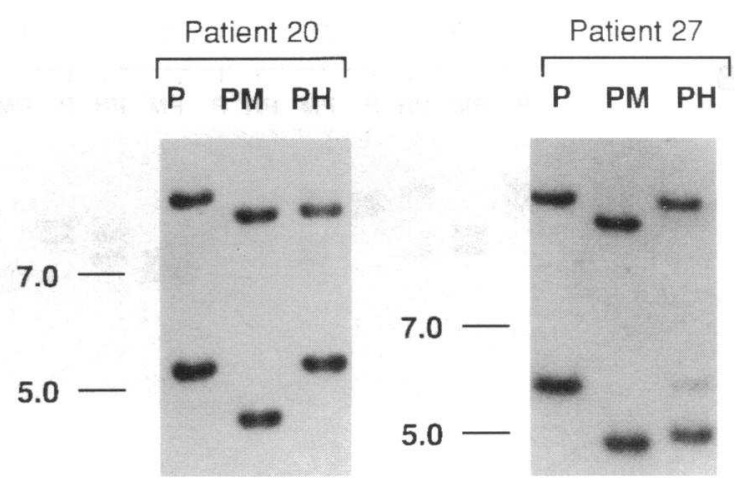

C

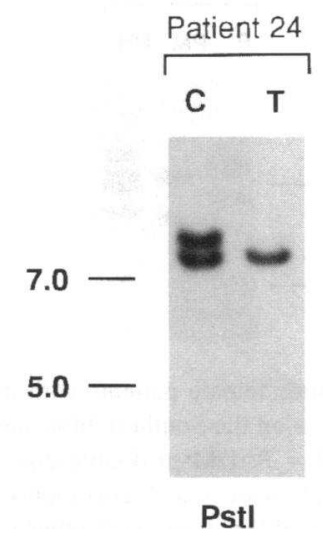

Figure 2. Representative clonal analyses of parathyroid tissue DNA using the M27 $\beta$ probe. Fragment sizes on the Southern blots are given in kilobases. Enzymes: $\mathrm{P}=\mathrm{PstI} ; \mathrm{PM}=\mathrm{PstI} / \mathrm{MspI}$ double digest; $\mathrm{PH}$ $=$ PstI/HpaII double digest. $(A)$ Patients 5 and 7: examples of nonfamilial primary parathyroid hyperplasia exhibiting monoclonal $\mathrm{X}$-inactivation patterns. Allelic cleavage ratios are 6.0 and 24, respectively. $(B)$ Patients 20 and 27: examples of uremic refractory parathyroid hyperplasia with monoclonal $\mathrm{X}$-inactivation patterns. Allelic cleavage ratios are 14 and 4.1, respectively. $(C)$ Monoclonality of a uremic patient's resected parathyroid arm graft. Lane $C$ : patient's normal leukocyte DNA cut with PstI alone, showing two distinguishable M27 $\beta$ alleles. Lane $T$ : DNA from this patient's parathyroid arm graft also cut with PstI alone, showing monoclonal loss of the upper M27 $\beta$ allele.

refractory secondary parathyroid hyperplasia were informative with the M27 $\beta$ probe, yielding 19 informative glands. 11 of the 19 glands exhibited a monoclonal X-inactivation pattern (Fig. 

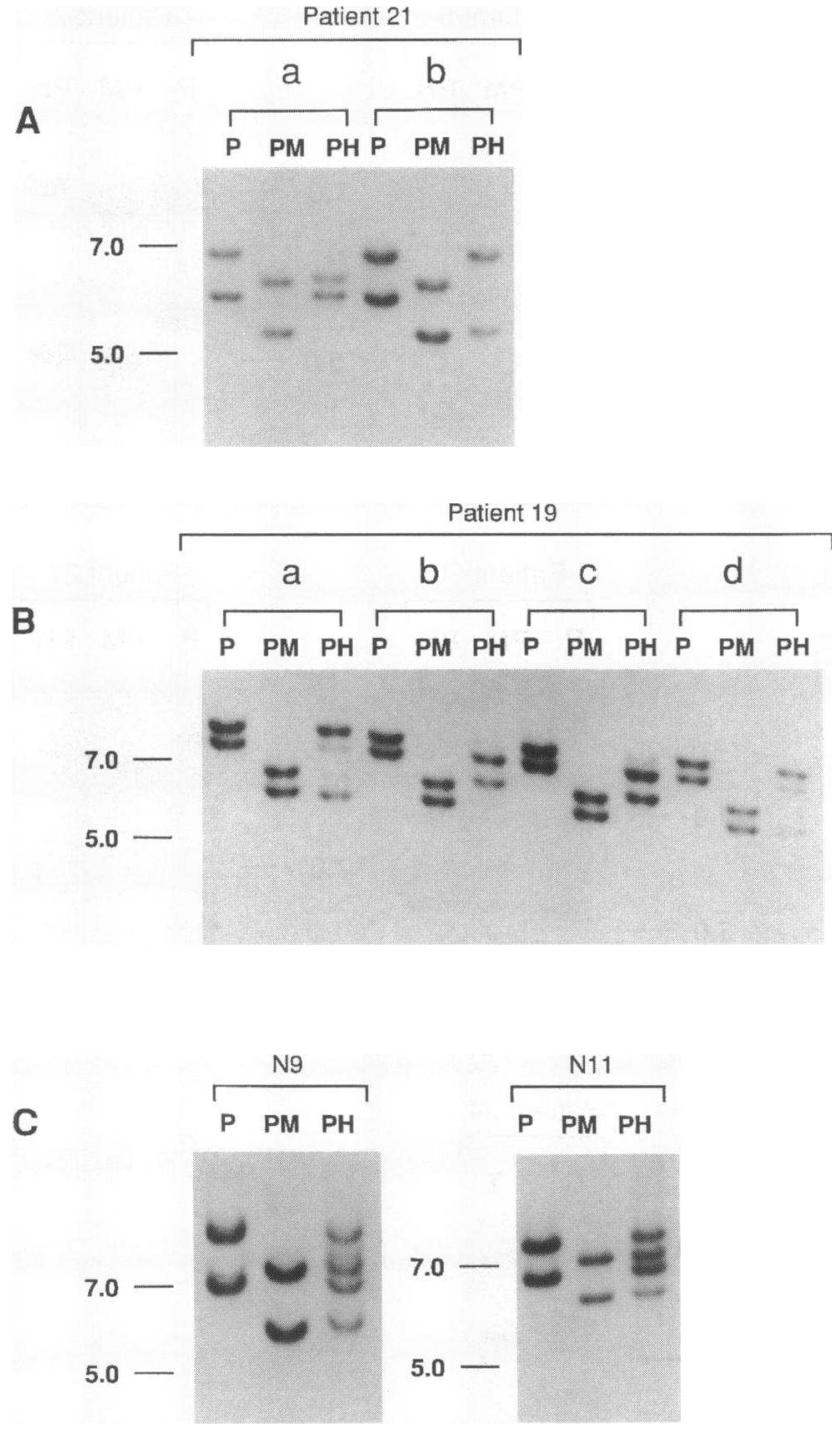

Figure 3. M27 $\beta$ clonal analyses of three female patients with uremic parathyroid hyperplasia. Fragment sizes on the Southern blots are given in kilobases. Enzymes: $\mathrm{P}=\mathrm{PstI} ; \mathrm{PM}=\mathrm{PstI} / \mathrm{MspI}$ double digest; $\mathrm{PH}$ $=$ PstI/HpaII double digest. $(A)$ Single patient with two monoclonal glands $(a$ and $b)$. Note that the glands differ from each other in the M27 $\beta$ allele that is clonally cleaved, underscoring that independent clonal events occurred in each gland. Allelic cleavage ratios are 5.1 and 4.8 , respectively. $(B)$ A single patient with three monoclonal glands ( $a$, $b$, and $c$ ); allelic cleavage ratios are $3.9,14$, and 28 , respectively. A fourth gland $(d)$ with cleavage ratio of 1.7 did not meet our stringent criteria for monoclonality. Again, different $\mathrm{X}$-inactivation patterns, here including both monoclonal and polyclonal patterns, are found among the glands of a single patient. (C) N9, N11: representative normal parathyroid glands exhibiting typical polyclonal X-inactivation patterns. Allelic cleavage ratios are 1.0 and 1.1 , respectively.

$2 B$ ), with an average allelic cleavage ratio of 10.3 (range 3.927.8 ). A 12th gland was also scored as monoclonal based upon its complete allelic loss at M27 $\beta$ (Fig. $2 C$ ). Of the 11 informative patients, $7(64 \%)$ had at least 1 monoclonal parathyroid neoplasm. It is interesting to note that in two patients with multiple monoclonal glands a given $\mathrm{M} 27 \beta$ allele was active in one tumor and inactive in another (example in Fig. 3, $A$ and
Table I. Nodular versus Generalized Parathyroid Hyperplasia in Uremic Hyperparathyroidism

\begin{tabular}{lcc}
\hline & Monoclonal glands & Polyclonalambiguous glands \\
\hline Nodular hyperplasia & 4 & 2 \\
Generalized hyperplasia & 8 & 5 \\
\hline
\end{tabular}

Comparison of monoclonality and polyclonality using the histological classification of nodular and generalized parathyroid hyperplasia.

$B$ ). This finding emphasizes the independent clonal origins of discrete tumors within the same patient. We found no correlation between monoclonality and histopathologic categories of generalized versus nodular hyperplasia in these patients (Table I). The 7 patients who harbored at least 1 detectably monoclonal tumor had a mean serum calcium of $11.2 \mathrm{mg} / \mathrm{dl}$, as compared with $10.0 \mathrm{mg} / \mathrm{dl}$ in those without a demonstrably monoclonal gland; this difference was not statistically significant $(P=0.27$, Student's $t$ test, Wilcoxon non-parametric test).

Normal controls. Peripheral blood leukocyte DNA from 24 of 29 patients was informative with $M 27 \beta$. In no case did normal leukocyte DNA yield a monoclonal M27 $\beta$ pattern (average allelic cleavage ratio 1.5 , range $1.0-2.2$ ). In addition, because tissue-specific differences in M27 $\beta$ clonality patterns have been described (9), we examined 14 informative normal parathyroid gland samples. Not one normal gland had a monoclonal $\mathrm{X}$-inactivation pattern, the average allelic cleavage ratio for this group being 1.7 (range 1.0-3.3) (Fig. $3 C$ ). These findings in polyclonal control tissues contrast sharply with the monoclonal patterns found in the pathologic parathyroid glands discussed above.

Allelic loss. The monoclonality of several tumors was able to be ascertained by an entirely independent means, that of assessment of clonal allelic loss of polymorphic DNA markers. Monoclonal loss of heterozygosity detectable with the M27 $\beta$ probe was found in one gland from a uremic patient (Fig. 2 $C)$. The tumor-specific allelic losses on the $\mathrm{X}$-chromosome in this case extended well beyond the $M 27 \beta$ region, evidenced by the finding of loss of heterozygosity at additional X-chromosome loci, namely DXS84, ARAF1, MAOB, DXS453, and DXS3.

DNA markers at 11q13, known to incur clonal allelic losses in a subset of parathyroid adenomas (2) and in MEN-1-related tumors $(2,3,24)$, were able to be assessed in 7 of the 16 female patients and 2 males with primary parathyroid hyperplasia (i.e., those for whom control blood leukocyte samples were available). Five of these nine patients were heterozygous (informative) with at least one of the 11 q13 probes tested. One informative example of primary hyperplasia, which had shown a polyclonal X-inactivation pattern, exhibited monoclonal loss of heterozygosity at $11 \mathrm{q} 13$ (data not shown).

For patients with uremic parathyroid hyperplasia, leukocyte control DNA was available from 11 females and 9 males, of whom 10 ( 7 females and 3 males ) were informative at an 11q13 marker locus. Of these 10 informative patients (total of 18 glands studied) none showed tumor-specific clonal loss of heterozygosity at 11q13, including the 1 uremic patient who had exhibited tumor-specific loss of heterozygosity with M27 $\beta$.

Familial primary parathyroid hyperplasia. We were also 
Table II. Summary of Parathyroid Tumor Clonality in Female Patients

\begin{tabular}{|c|c|c|c|c|c|}
\hline & \multicolumn{2}{|c|}{ Total informative } & \multirow{2}{*}{$\begin{array}{l}\text { Monoclonal } \\
\text { glands }\end{array}$} & \multirow{2}{*}{$\begin{array}{l}\text { Polyclonal/ } \\
\text { ambiguous } \\
\text { glands }\end{array}$} & \multirow{2}{*}{$\begin{array}{l}\text { Patients with } \\
\text { at least one } \\
\text { monoclonal } \\
\text { gland }\end{array}$} \\
\hline & Patients & Glands & & & \\
\hline $1^{\circ}$ Hyperplasia & 16 & 19 & 6 & 13 & $6(38 \%)$ \\
\hline $2^{\circ}$ Hyperplasia & 11 & 19 & 12 & 7 & $7(64 \%)$ \\
\hline
\end{tabular}

Clonality was detected on Southern blots by M27 $\beta$ X-inactivation analysis and by allelic loss at M27 $\beta$, D11S146, and PYGM loci. $1^{\circ}$ Hyperplasia $=$ nonfamilial primary parathyroid hyperplasia. $2^{\circ}$ Hyperplasia $=$ refractory secondary hyperparathyroidism of uremia.

able to study four patients with a family history of hyperparathyroidism but without a clear diagnosis of MEN-1. Two of the four glands from these four patients showed monoclonal allelic loss at M27 $\beta$ and also at 11q13, while the other two glands showed a polyclonal/ambiguous $\mathrm{X}$-inactivation pattern. These glands with $\mathrm{M} 27 \beta$ allelic loss, similar to the previously described gland from a uremic patient, had loss of heterozygosity at multiple loci spanning both the short and long arms of the $\mathrm{X}$-chromosome.

\section{Discussion}

We have demonstrated that a substantial proportion $(\geq 38 \%)$ of patients with primary parathyroid hyperplasia harbor a monoclonal neoplasm in at least one of their hypercellular parathyroid glands. An even larger group ( $\geq 64 \%$ ) of patients with the refractory secondary parathyroid hyperplasia of uremia who have failed medical therapy have at least one clonal parathyroid tumor (data summarized in Table II). In X-inactivation analyses only a finding of monoclonality is definitive, while a polyclonal pattern could be misleadingly seen for a variety of reasons (such as normal tissue admixture or aberrant patterns of DNA methylation in a truly monoclonal tumor, or the presence of two clonal populations with opposing $\mathrm{X}$-inactivation or allelic loss patterns, for example). In addition, the potential impact of sampling error can be considered, since in the uremic group, for example, about half of the resected glands were not available to us for DNA analysis. If a certain subset of these glands were demonstrably monoclonal, then the percentage of patients with at least one clonal tumor could have risen to $100 \%$ (but, of course, could not fall below the stated $64 \%$ even if no additional glands were monoclonal). Thus, it must be emphasized that even these impressively and unexpectedly high proportions of patients bearing abnormal clonal parathyroid tumors may be underestimates.

Monoclonality implies that somatic mutation of certain genes controlling cell proliferation occurred in a single parathyroid cell, conferring a selective growth advantage upon it and its progeny. In the present context, our data suggest that emergence of clonal expansions occurs commonly on a background of true generalized hyperplasia. Conceivably, the heightened proliferative rate in such hyperplasias increases the tissue's cumulative risk for the mitotic errors of DNA mutation, rearrangement, deletion, etc. To cite a possibly related example, in familial MEN-1, parathyroid tumors exhibiting clonal DNA losses in the putative MEN-1 gene region are common and might also evolve on a background of true hyperplasia $(2,3)$. The complication of clonal emergence may increase the chance that a clinically silent primary or controllable/reversible secondary hyperplasia becomes a clinically important disease that requires surgery. It is also possible that an impaired capacity for DNA repair, which has been described in uremic patients $(32,33)$, further increases the likelihood of clonal transformation in their parathyroid glands.

Histopathologic criteria have been inadequate for distinguishing parathyroid adenoma from hyperplasia (20). Our results raise the possibility that at least one reason may be that many hyperplastic glands are monoclonal and in essence are adenomas. Certainly, our findings highlight the inability of traditional clinico-pathologic indicators of parathyroid hyperplasia, based upon the existence of multigland disease, to predict true biologic (polyclonal) hyperplasia.

Some surgeons and pathologists have made a distinction between nodular and generalized forms of parathyroid hyperplasia, and this was done for our cases of uremic hyperparathyroidism. One key question is whether this controversial descriptive distinction, based upon gross and histopathologic criteria, reflects important biologic or clinical differences among the tumors. Interestingly, while the majority $(67 \%)$ of our glands with nodular histology was definitively monoclonal, a majority (62\%) of glands with generalized hyperplasia (no nodular component) was also unequivocally monoclonal. Because polyclonality cannot be specified as definitively as monoclonality with the X-inactivation method, it is possible that our results underestimate the true frequency of monoclonality in one or both of these categories; for example, virtually all nodular cases might be monoclonal. Obviously, the biological relevance of these descriptors is dramatically undercut by our finding of frequent monoclonal neoplasms (likely accompanied by increased functional autonomy) in both histologic categories.

What are the specific genes whose somatic mutation results in these clonal tumors? Subgroups of parathyroid adenomas contain rearrangement of the PRAD1/cyclin D1 oncogene (3436) or exhibit loss of a presumed tumor suppressor gene on $11 q 13$ (2) or 1p (37). While PRAD1 or 1p loci have not been assessed in parathyroid hyperplasia, Falchetti et al. (5) found allelic loss of 11q13 DNA markers, thereby demonstrating monoclonality, in only 2 of 12 uremic parathyroid glands. We found no examples of 11q13 allelic loss in 18 informative uremic glands, confirming that loss of a chromosome 11 tumor suppressor gene does not appear to be a common mechanism underlying what we show here to be the frequent development of monoclonal tumors in the setting of uremia. In sporadic primary parathyroid hyperplasia we found that one of four informative patients exhibited allelic loss at the 11q13 loci tested. Thus, the genetic loci responsible for the frequent monoclonality we observed in primary and uremic refractory secondary parathyroid hyperplasia in large part remain to be identified. Our novel finding of tumor-specific DNA loss at M27 $\beta$ and other $\mathrm{X}$-chromosome loci in three independent parathyroid tumors strongly suggests that somatic inactivation of an X-linked tumor suppressor gene may contribute to clonal outgrowths in at least some cases of parathyroid hyperplasia. This putative tumor suppressor gene may have a highly tissue-specific effect, since Xchromosome allelic losses have been described in only one other type of tumor, ovarian cancer (38). Additional studies 
of X-chromosome loss patterns in our tumor specimens may eventually help to pinpoint this gene.

Somatic mutation of genes playing a role in the physiological control of PTH synthesis or secretion could also be contributing. For example, a disturbance of the synthesis or expression of the vitamin D receptor gene (39) or the recently cloned calcium-sensing receptor gene (40) could lead to uncontrolled PTH secretion with clonal outgrowth.

Because the $\mathrm{X}$-inactivation method may underestimate the extent of monoclonality in any survey of tissues, it is conceivable that virtually all patients with severe uremic secondary hyperplasia who require parathyroidectomy (and perhaps those with clinically evident primary hyperplasia) harbor at least one clonal parathyroid tumor. The development of monoclonal tumor(s) may in fact distinguish this group from the majority of dialysis patients without refractory disease, in whom regression of hyperparathyroidism generally occurs after renal transplantation (41, 42), and from whom, of course, parathyroid tissue was unavailable for study. Available parameters such as PTH levels, duration of dialysis, etc., are not useful in making this distinction. Thus, the observed lack of statistically significant correlations between our surgical patients' clinical or laboratory parameters and the finding of monoclonality in their parathyroid tumor(s) might have been expected. Certainly our results reinforce the need for studies in which measures of functional autonomy like the calcium set-point in cultured cells are assessed together with the original gland's clonal status.

The cause of hypercalcemia in two of our patients was a hyperfunctioning autograft to the arm that proved to be a clonal neoplasm; molecular studies might eventually help in selecting or excluding particular parathyroid tissues at the time such autografts are contemplated. It might also become possible to perform echoguided fine needle puncture of hyperplastic parathyroid glands in uremic patients with severe hyperparathyroidism to obtain samples for clonality or mutation analyses. Positive results might permit the clinician to avoid unnecessary, longterm, and potentially hazardous medical treatment.

In summary, our data indicate that acquired clonal transformation is a frequent occurrence in the refractory parathyroid hyperplasia of chronic renal failure and in nonfamilial primary parathyroid hyperplasia, disease states which have eluded explanation. The widespread and unexpected presence of abnormal clonal parathyroid tumors in these patients likely plays a central pathogenetic role and has potential clinical importance.

\section{Acknowledgments}

We are grateful to Dr. Yvonne Boyd for providing the M27 $\beta$ probe. We thank Dr. C. Brocheriou, Pathology Service, Hôpital Saint Louis for light microscopic examinations of uremic parathyroid gland tissue; Dr. Eve-Reine Gagné, INSERM Unité 90 for help in the sampling of parathyroid glands; and Dr. Heio Harms, Massachusetts General Hospital for assistance with statistical analyses.

This work has been supported in part by the National Institutes of Health (CA-55909, DK-11794) and an American Cancer Society Faculty Research Award (FRA-391) to A. Arnold.

\section{References}

1. Arnold, A., C. E. Staunton, H. G. Kim, R. D. Gaz, and H. M. Kronenberg. 1988. Monoclonality and abnormal parathyroid hormone genes in parathyroid adenomas. N. Engl. J. Med. 318:658-662.
2. Friedman, E., K. Sakaguchi, A. Bale, A. Falchetti, E. Streeten, M. B. Zimering, L. S. Weinstein, W. O. McBride, Y. Nakamura, M.-L. Brandi, et al. 1989. Clonality of parathyroid tumors in familial multiple endocrine neoplasia type 1. N. Engl. J. Med. 321:213-218.

3. Thakker, R. V., P. Bouloux, C. Wooding, K. Chotai, P. M. Broad, N. K. Spurr, G. M. Besser, and J. L. H. O'Riordan. 1989. Association of parathyroid tumors in multiple endocrine neoplasia type I with loss of alleles on chromosome 11. N. Engl. J. Med. 321:218-224.

4. Galbraith, S., and L. Quarles. 1993. Tertiary hyperparathyroidism and refractory secondary hyperparathyroidism. In Primer on the Metabolic Bone Diseases and Disorders of Mineral Metabolism, 2nd ed. M. Favus, editor. Raven Press, New York. 159-163.

5. Falchetti, A., A. E. Bale, A. Amorosi, C. Bordi, P. Cicchi, S. Bandini, S. J. Marx, and M. L. Brandi. 1993. Progression of uremic hyperparathyroidism involves allelic loss on chromosome 11. J. Clin. Endocrinol. \& Metab. 76:139144.

6. Gagne, E. R., P. Ureña, S. Leite-Silva, J. Zingraff, A. Chevalier, E. Sarfati, C. Dubost, and T. Drüeke. 1992. Short and long-term efficacy of total parathyroidectomy with immediate autografting compared with subtotal parathyroidectomy in hemodialysis patients. J. Am. Soc. Nephrol. 3:1008-1017.

7. Biller, B. M. K., J. M. Alexander, N. T. Zervas, E. T. Hedley-Whyte, A. Arnold, and A. Klibanski. 1992. Clonal origins of adrenocorticotropin-secreting pituitary tissue in Cushing's disease. J. Clin. Endocrinol. \& Metab. 75:13031309.

8. Fearon, E. R., S. R. Hamilton, and B. Vogelstein. 1987. Clonal analysis of human colorectal tumors. Science (Wash. DC). 238:193-197.

9. Fey, M. F., H.-J. Peter, H. L. Hinds, A. Zimmermann, S. Liechti-Gallati, H. Gerber, H. Studer, and A. Tobler. 1992. Clonal analysis of human tumors with M27 $\beta$, a highly informative polymorphic X chromosomal probe. J. Clin. Invest. 89:1438-1444.

10. Fialkow, P. J. 1976. Clonal origin of human tumors. Biochim. Biophys. Acta. 458:283-321.

11. Gicquel, C., Y. Le Bouc, J.-P. Luton, F. Girard, and X. Bertagna. 1992. Monoclonality of corticotroph macroadenomas in Cushing's disease. J. Clin. Endocrinol. \& Metab. 75:472-475.

12. Herman, V., J. Fagin, R. Gonsky, K. Kovacs, and S. Melmed. 1990. Clonal origin of pituitary adenomas. J. Clin. Endocrinol. \& Metab. 71:1427-1433.

13. Hicks, D. G., V. A. LiVolsi, J. A. Neidich, J. M. Puck, and J. A. Kant 1990. Clonal analysis of solitary follicular nodules in the thyroid. Am. J. Pathol. 137:553-562.

14. Jacoby, L. B., E. T. Hedley-Whyte, K. Pulaski, B. R. Seizinger, and R. L. Martuza. 1990. Clonal origin of pituitary adenomas. J. Neurosurg. 73:731-735.

15. Namba, H., K. Matsuo, and J. A. Fagin. 1990. Clonal composition of benign and malignant human thyroid tumors. J. Clin. Invest. 86:120-125.

16. Schulte, H. M., E. H. Oldfield, B. Allolio, D. A. Katz, R. A. Berkman, and I. U. Ali. 1991. Clonal composition of pituitary adenomas in patients with Cushing's disease: determination by X-chromosome inactivation analysis. J. Clin. Endocrinol. \& Metab. 73:1302-1308.

17. Sidransky, D., P. Frost, A. Von Eschenbach, R. Oyasu, A. Preisinger, and B. Vogelstein. 1992. Clonal origin of bladder cancer. N. Engl. J. Med. 326:737740 .

18. Vogelstein, B., E. R. Fearon, S. R. Hamilton, and A. P. Feinberg. 1985. Use of restriction fragment length polymorphisms to determine the clonal origin of human tumors. Science (Wash. DC). 227:642-645.

19. Parfitt, A. M., G. D. Braunstein, and A. Katz. 1993. Radiation-associated hyperparathyroidism: comparison of adenoma growth rates, inferred from weight and duration of latency, with prevalence of mitosis. J. Clin. Endocrinol. \& Metab. 77:1318-1322.

20. Castleman, B., and S. I. Roth. 1978. Tumors of the parathyroid glands. In Atlas of Tumor Pathology, Second Series, Fascicle 14. W. H. Hartman, editor. Armed Forces Institute of Pathology, Washington, DC.

21. Harach, H. R., and B. Jasani. 1992. Parathyroid hyperplasia in tertiary hyperparathyroidism: a pathological and immunohistochemical reappraisal. Histopathology. 21:513-519.

22. LeCharpentier, Y., C. Dubost, J. Ferrand, A. Lavergne, M. E. Liard, E. Skrobala, and M. Wassef. 1983. Hyperparathyrö̈ies primitives. Technique d'examen et étapes du diagnostic des lésions parathyroïdiennes. Arch. Anat. Cytol. Pathol. 31:49-62.

23. Feinberg, A. P., and B. Vogelstein. 1983. A technique for radiolabeling DNA restriction endonuclease fragments to high specific activity. Anal. Biochem. 132:6-13.

24. Nakamura, Y., C. Larsson, C. Julier, C. Byström, B. Skogseid, S. Wells, K. Öberg, M. Carlson, T. Taggart, P. O'Connell, et al. 1989. Localization of the genetic defect in multiple endocrine neoplasia type I within a small region of chromosome 11. Am. J. Hum. Genet. 44:751-755.

25. Nakamura, Y., S. Gillilan, P. O'Connell, M. Leppert, G. M. Lathrop J.-M. Lalouel, and R. White. 1988. Isolation and mapping of a polymorphic DNA sequence pHBI59 on chromosome 11 [D11S146]. Nucleic Acids Res. 16:376. 
26. Boyd, Y., and N. J. Fraser. 1990. Methylation patterns at the hypervariable $\mathrm{X}$-chromosome locus DXS255 (M27 $\beta$ ): correlation with $\mathrm{X}$-inactivation status. Genomics. 7:182-187.

27. Brown, R. M., N. J. Fraser, and G. K. Brown. 1990. Differential methylation of the hypervariable locus DXS255 on active and inactive X chromosomes correlates with the expression of a human X-linked gene. Genomics. 7:215-221.

28. Fraser, N. J., Y. Boyd, and I. Craig. 1989. Isolation and characterization of a human variable copy number tandem repeat at Xcen-p11.2. Genomics. 5:144148.

29. Hendriks, R. W., M. E. M. Kraakman, R. G. J. Mensink, and R. K. B Schuurman. 1991. Differential methylation at the 5' and the 3' CCGG sites flanking the X chromosomal hypervariable DXS255 locus. Hum. Genet. 88:105 111

30. Hendriks, R. W., H. Hinds, Z. Y. Chen, and I. W. Craig. 1992. The hypervariable DXS255 locus contains a LINE-1 repetitive element with a CpG island that is extensively methylated only on the active $\mathrm{X}$ chromosome. Genomics. 14:598-603.

31. Hodges, E., W. M. Howell, Y. Boyd, and J. L. Smith. 1990. Variable Xchromosome DNA methylation patterns detected with probe M27 $\beta$ in a series of lymphoid and myeloid malignancies. Br. J. Haematol. 77:315-322.

32. Gengiz, K., A. M. W. Block, D. K. Hossfeld, R. Anthone, S. Anthone, and A. A. Sanberg. 1988. Sister chromatid exchange and chromosome abnormalities in uremic patients. Cancer Genet. Cytogenet. 36:55-67.

33. Malachi, T., D. Zevin, U. Gafter, A. Chagnac, H. Slor, and L. Levi. 1993. DNA repair and recovery of RNA synthesis in uremic patients. Kidney In 44:385-389.

34. Arnold, A., H. G. Kim, R. D. Gaz, R. L. Eddy, Y. Fukushima, M. G Byers, T. B. Shows, and H. M. Kronenberg. 1989. Molecular cloning and chromosome mapping of DNA rearranged with the parathyroid hormone gene in parathyroid adenoma. J. Clin. Invest. 83:2034-2040.
35. Motokura, T., T. Bloom, H. G. Kim, H. Jüppner, J. V. Ruderman, H. M. Kronenberg, and A. Arnold. 1991. A novel cyclin encoded by a bcl1-linked candidate oncogene. Nature (Lond.). 350:512-515.

36. Rosenberg, C. L., H. G. Kim, T. B. Shows, H. M. Kronenberg, and A. Arnold. 1991. Rearrangement and overexpression of D11S287E, a candidate oncogene on chromosome $11 \mathrm{q} 13$ in benign parathyroid tumors. Oncogene. 6:449453.

37. Cryns, V. L., S. M. Yi, H. Tahara, R. D. Gaz, and A. Arnold. 1995. Frequent loss of chromosome arm 1p DNA in parathyroid adenomas. Genes Chromosomes \& Cancer. In press.

38. Yang-Feng, T. L., S. Li, H. Han, and P. E. Schwartz. 1992. Frequent loss of heterozygosity on chromosome $\mathrm{Xp}$ and $13 \mathrm{q}$ in human ovarian cancer. Int. J. Cancer. 52:575-580.

39. Fukuda, N., H. Tanaka, Y. Tominaga, M. Fukagawa, K. Kurokawa, and $Y$. Seino. 1993. Decreased 1,25-dihydroxyvitamin $D_{3}$ receptor density is associated with a more severe form of parathyroid hyperplasia in chronic uremic patients. J. Clin. Invest. 92:1436-1443.

40. Brown, E. M., G. Gamba, D. Riccardi, M. Lombardi, R. Butters, O. Kifor, A. Sun, M. A. Hediger, J. Lytton, and S. C. Hebert. 1993. Cloning and characterization of an extracellular $\mathrm{Ca}^{2+}$-sensing receptor from bovine parathyroid. Nature (Lond.). 366:575-580.

41. Parfitt, A. M. 1982. Hypercalcemic hyperparathyroidism following renal transplantation: differential diagnosis, management, and implications for cell population control in the parathyroid gland. Miner. Electrolyte Metab. 8:92-112.

42. Steiner, R. W., M. Ziegler, N. A. Halasz, B. D. Catherwood, S. Manolagas, and L. J. Deftos. 1993. Effect of daily oral vitamin D and calcium therapy, hypophosphatemia, and endogenous 1,25-dihydroxycholecalciferol on parathyroid hormone and phosphate wasting in renal transplant recipients. Transplantation (Baltimore). 56:843-846. 